\title{
Obtención de líneas de pimiento (Capsicum annuum) progenitoras de híbridos F1, resistentes a enfermedades virales, a partir del estudio de cuatro sub-poblaciones
}

\author{
Yaritza Rodríguez, Tomás Depestre y Olimpia Gómez \\ Instituto de Investigaciones Hortícolas Liliana Dimitrova, Carretera Quivicán-Bejucal, km 331/2, Quivicán, \\ La Habana, Cuba. CP 33500.
}

\begin{abstract}
Y. Rodríguez, T. Depestre, and O. Gómez. 2007. Obtaining bell pepper lines (Capsicum annuum) resistant to viral diseases as progenitors of $\mathrm{F} 1$ hybrids, based on the study of four sub-populations. Cien. Inv. Agr. 34(3):237-242. Viral diseases constitute the main obstacle to bell pepper production in the world. In Cuba, pepper plants are primarily affected by the following viruses: Tobacco mosaic virus (TMV), Cucumber mosaic virus (CMV), Potato virus $Y$ (PVY), Tobacco etch virus (TEV), and Pepper venial mottled virus (PVMV). Since controlling viruses is becoming more and more difficult, breeders have had to resort to genetic control as the most efficient means of cultivar improvement. The need for selecting well-adapted multi-resistant lines bearing large fruits is a must if they are intended to be used as progenitors of more competitive $F_{1}$ s. Twenty seven lines grown on compacted ferric red soil were selected, analyzed, and cultivated following the procedures described in technical crop manuals. Four lines that were well adapted to tropical conditions, which bore large fruits, and with proven multi-resistance to the different viruses, were used as progenitors of the first $F_{1}$ Cuban pepper cultivar.
\end{abstract}

Key words: Hybrid, multi-resistance, pepper.

\section{Introducción}

Las especies de Capsicum fueron introducidas en Europa desde América. Son originarias de América Central y del Sur, siendo las primeras hortalizas empleadas como condimentos. Actualmente, en el comercio mundial de condimentos, ocupan el segundo lugar, tanto económica como productivamente, y se ubican después de la pimienta negra. El pimiento dulce, cultivado en todo el mundo se consume también en estado fresco. Algunos cultivares con alto nivel de pungencia (picantes), además de utilizarse como alimento, se emplean como medicamentos. Tanto el pimiento pungente como el dulce, enriquecen la dieta por sus

Recibido 10 de abril 2007. Aceptado 01 de octubre 2007.

'Dirigir correspondencia a Yaritza Rodríguez: yaritzadana@yahoo.com notables contenidos en vitaminas A y C (Depestre, 1999).

El cultivo de hortalizas tiene cada vez más importancia debido a la necesidad de diversificación y de mejorar la calidad de los productos alimenticios. El pimiento puede contribuir, no sólo al enriquecimiento nutricional de la alimentación de la población, sino también como fuente de ingresos de las familias rurales y como entrada de divisas para Cuba (Depestre, 2002). Por lo tanto, se hace necesario desarrollar cultivares, sostenibles y competitivos, para diversos propósitos comerciales, que respondan a las exigencias de los mercados existentes. Este trabajo de investigación tuvo por objetivo evaluar y seleccionar líneas de pimiento, caracterizados por producir frutos grandes y adaptados al clima tropical. Se espera utilizar estos cultivares como progenitores de híbridos $\mathrm{F}_{1}$ competitivos. 


\section{Materiales y métodos}

\section{Localidad y cultivo}

El presente trabajo se realizó en el Instituto de Investigaciones Hortícolas Liliana Dimitrova, Ministerio de la Agricultura, Cuba, situado en el Municipio de Quivicán, provincia La Habana (22 $23^{\prime}$ ' de longitud Oeste, 11 m.s.n.m) (IIHLD, 1997).

Los transplantes de cepellones, según el método de Casanova et al. (1999), se realizaron en octubre-diciembre (1999-2000), considerado como el período óptimo de plantación en Cuba. Se plantó en un suelo Ferralítico Rojo compactado en disposición espacial de $0,90 \mathrm{~m}$ x 0,30 m (CUBA-MINAG, 1995). Durante el cultivo, se efectuaron las labores establecidas en el instructivo técnico, a excepción del empleo de insecticidas para el control de áfidos, potenciales vectores de algunos virus (CUBAMINAG, 1984).

\section{Lineas experimentales y sub-poblaciones}

Se evaluaron 27 líneas de pimiento (obtenidas de la población base), las que mostraron en el campo, la baja incidencia y severidad a Tobacco mosaic virus (TMV), Potato virus Y (PVY), Tobacco etch virus (TEV) y Cucumber mosaic virus (CMV) durante los primeros ciclos de selección (C0-C6). Al mismo tiempo tuvieron el mayor número de frutos por plantas, peso promedio del fruto y rendimiento por planta (Cuadro 1).

Formación de la población base del programa $\operatorname{LIRA}\left(C_{0}\right)$

La población base se formó a partir de cruzamientos en $\mathrm{F}_{2} \mathrm{y}$ retrocruzamientos $(\mathrm{BC})$ (Depestre, 2002) (Cuadro 2). De acuerdo con la resistencia viral de sus progenitores, esta población base se dividió en cuatro subpoblaciones para ser ensayada frente a cuatro virus: 1. La sub-población LIRAT (TMV) se probó para resistencia al TMV $\mathrm{P}(0)$, a dos temperaturas; 2. La sub-población LIRAP (PVY, $\mathrm{P}(1,2)$ ) se ensayó para determinar el nivel de resistencia al PVY $\mathrm{P}(1,2)$ debido a que los genes que la confieren, se la otorgan
Cuadro 1. Características de las líneas de pimiento (Capsicum annum) utilizadas en este trabajo.

Table 1. Characteristics of the lines of peppers (Capsicum annum) used in this study.

\begin{tabular}{|c|c|c|c|}
\hline \multicolumn{4}{|c|}{ Líneas resistentes $\mathrm{a}^{1}$ : } \\
\hline $\begin{array}{c}\text { TMV } \\
\text { (LIRAV) }\end{array}$ & $\begin{array}{c}\text { PVY } \\
\text { (LIRAP) }\end{array}$ & $\begin{array}{c}\text { TEV } \\
\text { (LIRAE) }\end{array}$ & $\begin{array}{c}\text { CMV } \\
\text { (LIRAC) }\end{array}$ \\
\hline $\mathrm{Cu} 24$ & $\mathrm{Cu} 16$ & $\mathrm{Cu} 29$ & $\mathrm{Cu} 2$ \\
\hline $\mathrm{Cu} 26$ & $\mathrm{Cu} 17$ & $\mathrm{Cu} 32$ & $\mathrm{Cu} 5$ \\
\hline \multirow{11}{*}{$\mathrm{Cu} 28$} & & $\mathrm{Cu} 33$ & $\mathrm{Cu} 7$ \\
\hline & & $\mathrm{Cu} 34$ & $\mathrm{Cu} 8$ \\
\hline & & $\mathrm{Cu} 35$ & $\mathrm{Cu} 9$ \\
\hline & & $\mathrm{Cu} 36$ & $\mathrm{Cu} 10$ \\
\hline & & $\mathrm{Cu} 37$ & $\mathrm{Cu} 11$ \\
\hline & & $\mathrm{Cu} 38$ & $\mathrm{Cu} 100$ \\
\hline & & $\mathrm{L} \mathrm{Cu} 11$ & $\mathrm{Cu} 101$ \\
\hline & & & $\mathrm{Cu} 102$ \\
\hline & & & $\mathrm{Cu} 103$ \\
\hline & & & $\mathrm{Cu} 104$ \\
\hline & & & $\mathrm{L} \mathrm{Cu} 2$ \\
\hline
\end{tabular}

${ }^{1}$ Tobacco mosaic virus (TMV). Potato virus Y (PVY). Tobacco etch virus (TEV). Cucumber mosaic virus (CMV).

también a todos los patotipos conocidos; 3. La sub-población LIRAE (TEV) se probó para resistencia a TEV (CAU 4) y 4. La subpoblación LIRAC (CMV) se estudió, a nivel de plántulas, respecto de la resistencia a $\mathrm{CMV} / \mathrm{N}$ Fulton (CMV/N).

Para efectuar los cruzamientos en cada subpoblación, las plantas seleccionadas como resistentes se sembraron en macetas de $4 \mathrm{~L}$ y se mantuvieron aisladas.

En cada sub-población, la selección de líneas se hizo de acuerdo con las resistencias mostradas bajo condiciones de infección viral natural en el campo. El nivel de infección viral (V12), se expresó como sintomatología general de la planta en escala de 0 a 3 , correspondiendo 0 a planta sana, asintomática; 1 , a la presencia de un tenue mosaico; 2, a mosaico nítido; y 3, a un mosaico severo (Palloix y Depestre, 1998). Posteriormente, se comprobó la resistencia de éstas líneas seleccionadas a cada virus en condiciones controladas de laboratorio (A. Palloix, Comunicación personal, 2000).

En la generación $\mathrm{C}_{8}$ de cada sub-población, se seleccionaron futuras líneas progenitoras entre aquellas que resultaron resistentes a los virus 
estudiados y presentaron los mejores valores en número de frutos por planta, peso promedio del fruto y rendimiento por planta.

La comprobación de la resistencia a TMV, PVY, TEV y CMV se efectuó en los laboratorios de la Unité de Génetique et d’Amelioration des Fruits et Légumes, INRA (Institute Nationale Reserche Agronomique, Montfavet, Francia). Esta consistió en evaluar la sub-población LIRAT para resistencia a TMV (patotipo común, $\mathrm{P}(0)$ a 22 y $32^{\circ} \mathrm{C}$. En LIRAP se buscó resistencia al PVY $(\mathrm{p}(1,2))$, pues los genes que confieren resistencia a este patotipo, también la otorgan para los otros dos virus (A. Palloix, comunicación personal,1992). La subpoblación LIRAE se evaluó para resistencia a TEV (CAU4), por cuanto el aislado CAU4 de este virus se considera el más agresivo en el pimiento en Cuba (Depestre, 2002). En LIRAC se buscó resistencia a CMV Fulton y CMV/N a nivel de plántulas; el primer virus, provoca mosaico y el segundo necrosis foliar.

Las mejores líneas de cada sub-población, seleccionadas en $\mathrm{C}_{8}$ y autofecundadas, se utilizaron en la creación de híbridos $\mathrm{F}_{1}$.

Cuadro 2. Programa de mejoramiento de pimiento (Capsicum annuum) en Cuba: Genealogía de la población base de la sub-población LIRA.

Table 2. Pepper (Capsicum annuum) improvement program in Cuba: Genealogy of the base population of the LIRA sub-population.

\section{Genealogía}

F2 (SC $81 \times$ Vania)

F2 (SC $81 \times$ Vania)

BC1 (SC 81 x Vania) x Vania

BC1 (SC 81 x Vania)F2 x Vania

BC1 (SC $81 \times$ Vania) x Vania

F2 (SC $81 \times$ Yolo Wonder)

F2 (SC 81 x Samka)

F2 (SC $81 \times$ Samka)

F1 (SC 81 x Samka)

BC1 (SC 81 x Samka) x Samka

F2 (Español x Yolo Wonder)

F2 (Yolo Wonder x Medalla de Oro)

F2 (Flambeau x Vania)

F2 (Flambeau x Vania)

BC1 (PM 949 x Vania) x Vania

BC1 (PM 949 x Vania)F2 x Vania

\section{Evaluación}

En este trabajo se evaluaron los siguientes caracteres agronómicos: 1 . Número de frutos por planta (V1), 2. Peso promedio del fruto (V2), determinado como promedio de tres frutos maduros (rojos) por planta, y 3, Rendimiento por planta (V3), expresado como número de frutos multiplicado por el peso promedio del fruto.

\section{Diseño y análisis estadísticos}

El experimento fue dispuesto en bloques completos al azar con cuatro repeticiones. Para la selección de las mejores líneas dentro de cada una de las sub-poblaciones se realizó un análisis de varianza de clasificación simple, empleando StatGraphics Plus 5.0 (Statistical Graphics Corp., Manugistics, Inc., Rokville, EUA, 2000). Las medias se separaron mediante la prueba de Tukey $(\mathrm{p}<0,05)$.

\section{Resultados y discusión}

En cada una de las sub-poblaciones, y de acuerdo con los resultados de los análisis de varianza, se seleccionaron cuatro líneas que mostraron una alta productividad con la menor incidencia de virosis en la planta. Estas líneas se emplearon como progenitoras de los primeros híbridos $F_{1}$ de pimiento en Cuba (Cuadro 3).

En el caso de la sub-población LIRAC, se seleccionó la línea $\mathrm{Cu} 103$, con un promedio de 15,08 fruto planta $^{-1}, 121,27 \mathrm{~g}$ de peso promedio del fruto, $1,57 \mathrm{~kg} \cdot$ planta $^{-1}$ de rendimiento y 0,9 como índice de virosis. En la sub-población LIRAE, se seleccionó la línea $\mathrm{Cu} 32$ con un promedio de 18,9 fruto planta $^{-1}$, frutos de 102 $\mathrm{g}$, rendimiento de $1,46 \mathrm{~kg} \cdot \mathrm{planta}^{-1}$, e índice de virosis igual a cero. En LIRAV, se seleccionó la línea $\mathrm{Cu} 17$, con un promedio de 18,45 fruto planta $^{-1}$, un peso de los frutos de 61,25 $\mathrm{g}$, y un rendimiento de $1,13 \mathrm{~kg} \cdot$ planta $^{-1}$. El índice de virosis fue igual a 1 y en LIRAP se seleccionó la línea $\mathrm{Cu} 28$ con un promedio de 18,85 fruto planta $^{-1}, 87,12 \mathrm{~g}$ de peso promedio de los frutos, y rendimiento de $1,42 \mathrm{~kg} \cdot$ planta $^{-1}$. El índice de virosis también fue 1.

Elanálisis anterior, permitióla selección efectiva 
Cuadro 3. Líneas de cada sub-población de pimiento (Capsicum annuum) en la generación C8.

Table 3. Lines of each sub-population of pepper (Capsicum annuum) in the C8 generation.

\begin{tabular}{|c|c|c|c|c|}
\hline Líneas & $\begin{array}{l}\text { Frutos } \\
\text { fruto'planta }^{-1}\end{array}$ & $\begin{array}{l}\text { Peso promedio del fruto } \\
\mathrm{g}\end{array}$ & $\begin{array}{l}\text { Rendimiento } \\
\mathrm{kg} \cdot \text { planta }^{-1}\end{array}$ & $\begin{array}{l}\text { Indice } \\
\text { viral }^{1}\end{array}$ \\
\hline & & Sub-población LIRAC & & \\
\hline $\mathrm{Cu} 2$ & $13,76 b^{2}$ & $114,63 b^{2}$ & 1,13 bcde $^{2}$ & $1,9 b^{2}$ \\
\hline $\mathrm{Cu} 5$ & $14,25 \mathrm{~b}$ & $72,75 \mathrm{de}$ & 1,03 cde & $1,0 \mathrm{c}$ \\
\hline $\mathrm{Cu} 7$ & 10,62 ef & $114,5 \mathrm{~b}$ & $1,21 \mathrm{bc}$ & $1,0 \mathrm{c}$ \\
\hline $\mathrm{Cu} 8$ & $11,92 \mathrm{bc}$ & $63,07 \mathrm{gh}$ & $0,75 \mathrm{f}$ & $3,0 \mathrm{a}$ \\
\hline $\mathrm{Cu} 9$ & $16,57 \mathrm{a}$ & $57,0 \mathrm{ij}$ & $0,95 \mathrm{e}$ & $2,9 \mathrm{a}$ \\
\hline $\mathrm{Cu} 10$ & 9,97 ef & 60,15 hi & $0,60 \mathrm{fg}$ & $2,0 \mathrm{~b}$ \\
\hline $\mathrm{Cu} 11$ & $9,92 \mathrm{f}$ & $55,1 \mathrm{k}$ & $0,54 \mathrm{~g}$ & $1,9 \mathrm{~b}$ \\
\hline $\mathrm{Cu} 100$ & $8,97 \mathrm{f}$ & $74,72 \mathrm{~d}$ & $0,67 \mathrm{fg}$ & $2,9 \mathrm{a}$ \\
\hline $\mathrm{Cu} 101$ & 10,15 ef & $72,15 \mathrm{def}$ & $1,23 \mathrm{~b}$ & $3,0 \mathrm{a}$ \\
\hline $\mathrm{Cu} 102$ & $10,80 \mathrm{~cd}$ & $106,52 \mathrm{c}$ & $1,15 \mathrm{bcd}$ & $0,9 \mathrm{c}$ \\
\hline $\mathrm{Cu} 103$ & $15,08 \mathrm{ab}$ & $121,27 \mathrm{a}$ & $1,57 \mathrm{a}$ & $0,9 \mathrm{c}$ \\
\hline $\mathrm{Cu} 104$ & $14,67 \mathrm{ab}$ & $67,62 \mathrm{fg}$ & $0,98 \mathrm{de}$ & $0,9 \mathrm{c}$ \\
\hline \multirow[t]{2}{*}{ Lcu 2} & $9,95 \mathrm{f}$ & 68,5 ef & $0,68 \mathrm{fg}$ & $0,9 \mathrm{c}$ \\
\hline & & Sub-población LIRAE & & \\
\hline $\mathrm{Cu} 29$ & $14,32 \mathrm{de}$ & $70,46 \mathrm{bc}$ & $1,33 \mathrm{bc}$ & $0,00 \mathrm{~d}$ \\
\hline $\mathrm{Cu} 32$ & $18,9 \mathrm{abc}$ & $102,0 \mathrm{a}$ & $1,46 \mathrm{a}$ & $0,00 \mathrm{~d}$ \\
\hline $\mathrm{Cu} 33$ & $16,5 \mathrm{~cd}$ & $70,77 \mathrm{bc}$ & 1,16 bcde & $0,00 \mathrm{~d}$ \\
\hline $\mathrm{Cu} 34$ & $17,09 \mathrm{bc}$ & $60,75 \mathrm{e}$ & $1,11 \mathrm{cde}$ & $1,08 \mathrm{c}$ \\
\hline $\mathrm{Cu} 35$ & $15,55 \mathrm{de}$ & $74,42 \mathrm{bc}$ & $1,2 \mathrm{bcd}$ & $2,93 \mathrm{a}$ \\
\hline $\mathrm{Cu} 36$ & $18,9 \mathrm{ab}$ & $61,6 \mathrm{de}$ & $1,25 \mathrm{bc}$ & $2,98 \mathrm{a}$ \\
\hline $\mathrm{Cu} 37$ & $20,72 \mathrm{a}$ & $72,85 \mathrm{bc}$ & $1,36 \mathrm{bc}$ & $2,98 \mathrm{a}$ \\
\hline $\mathrm{Cu} 38$ & 13,37 ef & $68,75 \mathrm{~cd}$ & $0,91 \mathrm{de}$ & $2,0 \mathrm{~b}$ \\
\hline \multirow[t]{2}{*}{$\mathrm{LCu} 11$} & $11,9 \mathrm{f}$ & $76,5 \mathrm{~b}$ & $0,86 \mathrm{e}$ & $0,00 \mathrm{~d}$ \\
\hline & & Sub-población LIRAP & & \\
\hline $\mathrm{Cu} 24$ & $11,57 \mathrm{c}$ & $106,13 \mathrm{a}$ & $1,53 \mathrm{a}$ & $2,9 \mathrm{a}$ \\
\hline $\mathrm{Cu} 26$ & $14,36 \mathrm{bc}$ & $117,45 \mathrm{a}$ & $1,40 \mathrm{a}$ & $1,0 \mathrm{~b}$ \\
\hline \multirow[t]{2}{*}{$\mathrm{Cu} 28$} & $18,85 \mathrm{a}$ & 87,12 a & $1,42 \mathrm{a}$ & $1,0 \mathrm{~b}$ \\
\hline & & Sub-población LIRAV & & \\
\hline Cu16 & $15,76 \mathrm{~b}$ & 68,96 a & $1,24 \mathrm{a}$ & $2,9 \mathrm{a}$ \\
\hline $\mathrm{Cu} 17$ & $18,45 \mathrm{a}$ & $61,25 \mathrm{~b}$ & $1,13 \mathrm{a}$ & $1,0 \mathrm{~b}$ \\
\hline
\end{tabular}

${ }^{1}$ Nivel de infección viral expresado como sintomatología general de la planta en escala de 0 a 3 , donde 0 = planta sana, asintomática, $1=$ presencia de un tenue mosaico, 2 = mosaico nítido y 3 = mosaico severo.

${ }^{2}$ Promedios que comparten una misma letra no son estadísticamente diferentes entre si, según la Prueba de Tukey (p < 0,05$)$.

${ }^{\prime}$ Level of viral infection expressed as general symptomatology of the plant on a scale of 0 to 3 , where $0=$ healthy asymptomatic plant, $I=$ presence of slight mosaic virus, 2 = clear mosaic virus and $3=$ severe mosaic virus.

${ }^{2}$ Means followed by the same letters are not statistically different from each other, according to Tukey's test ( $\left.p<0.05\right)$.

de cuatro líneas de pimientos resistentes a CMV, TEV, PVY y TMV, adaptadas al trópico. Sus principales características se resumen en el Cuadro 4.

La estrategia seguida en este programa de mejoramiento permitió la mejora gradual de las resistencias a virus, conjuntamente con la de los caracteres agronómicos de interés comercial. De este modo fue posible obtener líneas promisorias de pimiento para su inclusión como progenitoras en el programa de mejoramiento genético de esta especie. Con anterioridad, se obtuvieron cultivares de pimiento de frutos pequeños 'SC 81' resistentes a TMV y PVY (Espinosa et al., 1992); 'Español Liliana' de frutos grandes resistente a TMV (Depestre et al., 1997); y 'Tropical CW-3' (Muñoz de Con, comunicación personal, Instituto de Investigaciones Fundamentales de la Agricultura Tropical Alejandro de Humbolt. La Habana, Cuba). Estos cultivares han sido ampliamente utilizados en la producción de pimiento en Cuba (Depestre, 2002). 
La obtención de líneas de pimiento resistentes a los diferentes virus estudiados y la ocurrencia de resistencia múltiple en algunas de ellas, es un logro importante en el mejoramiento genético del pimiento en Cuba. La frecuente evolución de los patógenos en las áreas tropicales, capaces de vencer la resistencia genética en el cultivo del pimiento, hace necesario la obtención de resistencia durable (Ahmed et al., 2001; Depestre, 2002; Mitidien y Polack, 2005; Rodríguez et al., 2002).

Por lo tanto, la selección de líneas multiresistentes de pimiento, y adaptadas a las condiciones tropicales que caracterizan a Cuba, representa un importante aporte al mejoramiento de esta especie hortícola. Estas líneas correspondieron a $\mathrm{Cu} 17$ resistente a PVY y TMV; $\mathrm{Cu} 28$ resistente a PVMV y TMV; $\mathrm{Cu} 29, \mathrm{Cu} 32$ y $\mathrm{Cu} 33$ resistente TEV y TMV y $\mathrm{Cu} 103$ resistente a CMV y TMV. En consecuencia, es posible utilizar estas líneas como progenitoras en programa de obtención de híbridos $\mathrm{F}_{1}$ de pimiento (Cuadro 4).

\section{Resumen}

Las enfermedades virales constituyen el principal obstáculo para el desarrollo del pimiento (Capsicum annuum) en el mundo. En Cuba, lo afectan principalmente el virus del mosaico del tabaco (TMV), el virus del mosaico del pepino (CMV), el virus $\mathrm{Y}$ de la papa (PVY), el virus del grabado del tabaco (TEV) y el virus del moteado de las venas del pimiento (PVMV). Dado que su control se hace cada vez más difícil, los fito-mejoradores han tenido que recurrir al control genético como vía más eficiente para lograr el desarrollo de este cultivo. La necesidad de seleccionar líneas de pimiento multi-resistentes a las principales enfermedades, de frutos grandes y de buena adaptación, cobra mayor importancia cada día, para ser utilizados como progenitores de híbridos $F_{1}$ más competitivos. Se analizaron 27 líneas de pimiento cultivadas en un suelo Ferralítico Rojo Compactado, efectuándose las labores culturales comúnmente recomendadas para este cultivo en Cuba. Se seleccionaron cuatro líneas con multi-resistencia comprobada a los diferentes virus, de frutos grandes y adaptados al trópico, las que se usaron como progenitores de los primeros híbridos $\mathrm{F}_{1}$ cubanos de pimiento.

Palabras claves: híbridos, multi-resistencia, pimiento.

Cuadro 4. Líneas seleccionadas en las diferentes sub-poblaciones de pimiento (Capsicum annuum).

Table 4. Selected lines in the different pepper sub-populations (Capsicum annuum).

\begin{tabular}{|c|c|c|c|}
\hline Línea & Sub-población & Características & Resistente $\mathrm{a}^{1}$ \\
\hline $\mathrm{Cu} 28$ & LIRAV & $\begin{array}{l}\text { Número de frutos: } 18,8 \text { fruto } \text { planta }^{-1} \\
\text { Rendimiento: } 1,4 \mathrm{~kg} \cdot \text { planta }^{-1} \\
\text { Indice viral: } 1,0\end{array}$ & PVMV y TMV \\
\hline $\mathrm{Cu} 16$ & LIRAP & $\begin{array}{l}\text { Número de frutos } 18,4 \text { fruto planta } a^{-1} \\
\text { Indice viral: } 0,9\end{array}$ & PVY y TMV \\
\hline $\mathrm{Cu} 32$ & LIRAE & $\begin{array}{l}\text { Largo del fruto: } 6,4 \mathrm{~cm} \\
\text { Peso del fruto: } 102,0 \mathrm{~g} \\
\text { Rendimiento: } 1,4 \mathrm{~kg} \cdot \text { planta }^{-1} \\
\text { Indice viral: } 0 .\end{array}$ & TEV y TMV \\
\hline Cu 103 & LIRAC & $\begin{array}{l}\text { Número de frutos: } 15,8 \text { fruto } \text { planta }^{-1} \\
\text { Largo del fruto: } 9,3 \mathrm{~cm} \\
\text { Indice viral: } 0,9\end{array}$ & CMV y TMV \\
\hline
\end{tabular}

${ }^{1}$ Resistencia de campo comprobada en el Laboratorio de la Unité de Génetique et d'Amelioration des Fruits et Légumes del INRA, Montfavet, Francia (Palloix, 2002, Comunicación personal). Tobacco mosaic virus (TMV), Potato virus Y (PVY), Tobacco etch virus (TEV), Cucumber mosaic virus (CMV) y Pepper venial mottled virus (PVMV).

${ }^{\prime}$ Field resistance was confirmed by laboratory tests at the Laboratory of the Unité de Génetique et d'Amelioration des Fruits et Légumes del INRA, Montfavet, France (Palloix, 2002, Personal communication). Tobacco mosaic virus (TMV), Potato virus Y (PVY), Tobacco etch virus (TEV), Cucumber mosaic virus (CMV) and Pepper venial mottled virus (PVMV). 


\section{Literatura citada}

Ahmed, E.A., A.M. Daubeze, D. Lafortune, . Depestre; W.R., Nono, C. Duranton, T. Berke, N.B. Gaddagimath, G. Nemouchi, and A. Palloix 2001. Constructing multiresistant genotypes of sweet pepper for cultivation in the tropics. EUCARPIA Capsicum and Eggplant. Paris, Francia. p. 293-297.

Casanova A., O. Gómez, H. Cardoza, J.C.Hernández, C. Murquido y M. León. 1999. Guía Técnica para la Producción de Tomate. IIHLD (Instituto de Investigaciones Hortícolas Liliana Dimitrova), Quivicán, La Habana, Cuba. 4 p.

CUBA-MINAG. 1995 Instructivo Técnico de Organopónico. Ciudad Habana. MINAG (Ministerio de la Agricultura), La Habana, Cuba. $50 \mathrm{p}$.

CUBA-MINAG. 1984. Instructivo técnico del cultivo del pimiento. La Habana. Dirección Nacional de Cultivos Varios. Ministerio de la Agricultura. Cuidad de la Habana, Cuba 29 p.

Depestre, T., J. Espinosa, V. Camino y R. González. 1997. Pimiento y berenjena. En. p. 20-22. Memorias 25 Aniversario-La Habana: Editorial Liliana. La Habana, Cuba.
Depestre, T. 2002. Construcción de multi-resistencia a enfermedades virales y adaptación al trópico en genotipos de pimiento (Capsicum annuиm L.) y su aplicación. www.cuba.cu/ciencia/acc/ agrarias 2002_resumen.htm. (Consultado el 3 de mayo, 2007).

Espinosa, J., T. Depestre y V. Camino. 1992. Una nueva variedad resistente de pimiento. Agricultura Tropical 2:13 -14.

IIHLD. 1997. Memorias 25 Aniversarios. Localización, clima y suelos. Instituto de Investigaciones Hortícolas Liliana Dimitrova. Editorial Liliana, La Habana, Cuba. 98p.

Mitidien, M. y Polack, L.A. 2005. Guía de monitoreo $\mathrm{y}$ reconocimiento de plagas, enfermedades $\mathrm{y}$ enemigos emergentes de tomate y pimiento. Estación Experimental Agropecuaria. San Pedro. INTA, Buenos Aires, Argentina. 110 pp.

Rodríguez, Yorman; Rangel, E., Centeno, F., Mendoza, A. y Parra, A. 2002. Virus diseases affecting sweet pepper (Capsicum annum) in Quibor Valley, Venezuela. Proc. Of the $16^{\text {th }}$ Int. Pepper Conference. Tampico, Tamaulipas. November, p.12-1. 